\title{
HPTLC-Densitometric and RP-HPLC Method Development and Validation for Determination of Salbutamol Sulphate, Bromhexine Hydrochloride and Etofylline in Tablet Dosage Forms
}

\author{
Ankit Tyagi ${ }^{1}$, Nitin Sharma ${ }^{1}$, Karan Mittal ${ }^{2}$, Rajashree Mashru ${ }^{2}$, Tilakraj Bhardwaj ${ }^{1}$, Jai Malik ${ }^{1}$ and Arti Thakkar ${ }^{\star \star}$ \\ II. S. F. College of Pharmacy, Ferozepur Road, Ghal Kalan, Punjab, India \\ ${ }^{2}$ Pharmacy Department, Faculty of Technology and Engineering, The M.S. University of Baroda, Kalabhavan, Vadodara, Gujarat, India
}

\begin{abstract}
Different HPTLC-densitometric and RP-HPLC methods are developed for the simultaneous determination of salbutamol sulphate, bromhexine hydrochloride and etofylline in pharmaceutical tablets. HPTLC method was based on separation of all three drugs followed by densitometric measurements of their spots at $275 \mathrm{~nm}$ using CAMAG, TLC scanner III. The separation was carried out on Merck HPTLC aluminium plates of silica gel 60 F254, using acetone: methanol: formic acid $(9: 3: 0.01)$ as mobile phase at room temperature $\left(25 \pm 2^{\circ} \mathrm{C}\right)$. The HPLC separation was carried out using a mobile phase consisting of $0.02 \mathrm{M}$ ammonium acetate buffer: organic phase (where organic phase $\mathrm{MeOH}: \mathrm{ACN}$ in ratio of 70:30) adjusted to $\mathrm{pH} 4.5$ with gradient elution. The column used was Waters Spherisorb $\otimes \mathrm{C}_{18}$ bonded with $5 \mu \mathrm{m}(4.6 \times 250 \mathrm{~mm})$ with a flow rate of $1 \mathrm{~mL} \mathrm{~min}{ }^{-1}$ and UV detection at $275 \mathrm{~nm}$ simultaneously. The mean recovery ofboth HPTLC and HPLC methods were found to be within 99.44 to $99.85 \%$ w/w. Both HPTLCdensitometric and RP-HPLC methods were statistically validated and can be used for analysis of combined dose tablet formulation containing salbutamol sulphate, bromhexine hydrochloride and etofylline.
\end{abstract}

Keywords: Salbutamol sulphate; Bromhexine hydrochloride; Etofylline; HPTLC; HPLC; UV detection

Abbreviations: $\mathrm{BH}-$ Bromhexine hydrochloride; SSSalbutamol Sulphate; ET- Etofylline; HPLC- High Performance Liquid Chromatography; HPTLC- High Performance Thin Layer Chromatography; GAA- Glacial acetic acid

\section{Introduction}

Salbutamol sulphate (SS), as shown in Figure 1 chemically known as bis [(1RS)-2-[(1, 1-dimethylethyl) amino]-1-[4-hydroxy3-(hydroxymethyl) phenyl] ethanol] sulphate, is beta adenocepter agonist. It is used for the relief of bronchospasm in condition such as asthma [1,2] and chronic obstructive pulmonary disease $[3,4]$. The smooth muscles are relaxed by the increase in the intracellular cyclic adenosine monophosphate [5-7]. Bromhexine hydrochloride (BH)as shown in Figure 1, N-(2-amino-3, 5-dibromobenzyl)-N methyl cychlohexanamine hydrochloride, is an expectorant use in the treatment of various respiratory disorders. Etofylline (ET) as shown in Figure 1, 7-(2-hydroxyethyl)-1, 3-dimethyl-3, 7-dihydro-1, 4-purine-2, 6-dione, is a xanthine bronchodilator used for the treatment of respiratory diseases and asthma in combination with SS. SS [8], BH [8] and ET [8] are official in BP. Official methods involve determination of SS, BH and ET using Potentiometry.SS, BH and ET as component of a multi ingredient formulation and has been reported to be estimated by some spectroscopic and HPLC methods either single or in combination simultaneously [9-15]. One spectroscopic method has been reported for the determination of SS along with $\mathrm{BH}$ and ET in combined dosage forms [16]. The tertiary combination SS, BH and ET, is not yet official in any pharmacopoeia. As par literature, no RP-HPLC and HPLC methods could be traced for the analysis of SS, BH and ET in their combined dosage forms. Therefore simple, rapid, economical and reliable RP-HPLC method for estimation of these drugs in mixture seemed to be necessary. All the analytical and validation procedures followed in the present study were as per ICH guidelines $[17,18]$.

\section{Experimental}

\section{Instruments}

Camag HPTLC system equipped with a sample applicator Linomat 5 TLC Scanner III, Reprostar and Wincats 4.02 integration software (Switzerland), twin trough glass development chamber, Ultrasonic cleaner (Sterylmedi-equip systems) and water purification system ELIX 03 (MILLIPORE, USA) were used during study.HPLC system of Waters (Milford, USA) composed of 515 series pumps combined with Waters 2707 autosampler along with Waters PDA 2998 series photodiode array detector set at wavelength range 190-800 $\mathrm{nm}$ with column from Waters Spherisorb ${ }^{\circ} \mathrm{C}_{18}$ bonded with $5 \mu \mathrm{m}(4.6 \times 250 \mathrm{~mm})$ coupled with EMPOWER-2 software recording and processing of chromatographic data was used.

\section{Chemicals and reagents}

SS, BH and ET were supplied as gift sample from FDC Ltd. (Mumbai, India) and marketed formulation of Eto-salbetol-10 (Batch Number-BTK0017, Kare Labs Pvt. Ltd., Goa, India) was procured from the local drug store, Moga, Punjab. Acetonitrile, methanol, water, ammonium acetate and glacial acetic acid (GAA) were purchased from Rankem (New Delhi, India). All these chemicals and solvents

*Corresponding author: Arti R Thakkar, I. S. F. College of Pharmacy, Ferozepur Road, Ghal Kalan, Moga 142 001, Punjab, India, Tel: +91 1636 324200; Fax: +91 1636 236564; E-mail: artirthakkar@gmail.com

Received January 22, 2015; Accepted March 03, 2015; Published March 10 2015

Citation: Tyagi A, Sharma N, Mittal K, Mashru R, Bhardwaj T, et al. (2015) HPTLC-Densitometric and RP-HPLC Method Development and Validation for Determination of Salbutamol Sulphate, Bromhexine Hydrochloride and Etofylline in Tablet Dosage Forms. Pharm Anal Acta 6: 350. doi:10.4172/2153-2435.1000350

Copyright: () 2015 Tyagi A, et al. This is an open-access article distributed under the terms of the Creative Commons Attribution License, which permits unrestricted use, distribution, and reproduction in any medium, provided the original author and source are credited. 
Citation: Tyagi A, Sharma N, Mittal K, Mashru R, Bhardwaj T, et al. (2015)HPTLC-Densitometric and RP-HPLC Method Development and Validation for Determination of Salbutamol Sulphate, Bromhexine Hydrochloride and Etofylline in Tablet Dosage Forms. Pharm Anal Acta 6: 350. doi:10.4172/2153-2435.1000350

Page 2 of 9

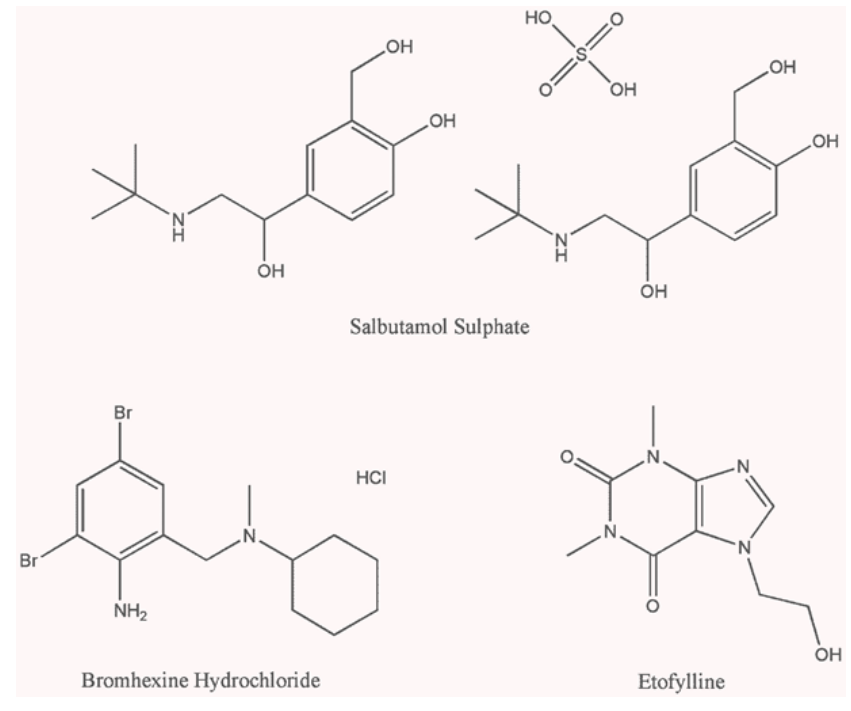

Figure 1: Structure of SS, ET and BH

were of HPLC grade and were used without any further purification. All the required solutions were prepared in HPLC grade water. HPLC grade water was obtained from water purification systems ELIX 03 (MILLIPORE, USA). Unless otherwise specified, all solutions were filtered through a $0.2 \mu \mathrm{m}$ Ultipor ${ }^{\circledR} \mathrm{N}^{\circ} 6^{\circ}$ Nylon 6,6 membrane filter (Pall Life Sciences, USA) prior to use. Pre-coated silica gel $60 \mathrm{~F}_{254}$ TLC aluminium backed plates $(20 \times 20 \mathrm{~cm}, 0.2 \mathrm{~mm}$ thick) were purchased from E. Merck Ltd. (Germany).

\section{Chromatographic conditions}

HPTLC plates were developed with acetone: $\mathrm{MeOH}$ : formic acid (9: 3: 0.01) as mobile phase. Chromatographic plate was developed up to the top (over a distance of $8 \mathrm{~cm}$ ) in the usual ascending way. Chromatographic tank was saturated with mobilephase in the usual manner. After elution, plate was air dried and scanned at $275 \mathrm{~nm}$ as under the described instrumental parameters. Samples were spotted as a band of $8 \mathrm{~mm}$ width on pre-coated silica gel aluminium backed plate $60 \mathrm{~F}-254$ with $200 \mu \mathrm{m}$ thickness. Application rate of $80 \mathrm{nl} \mathrm{s}^{-1}$ was employed and space between bands was $10 \mathrm{~mm}$. Linear ascending development was carried out in a twin trough glass chamber previously saturated with mobile phase for $20 \mathrm{~min}$. Densitometric scanning was performed on camag TLC scanner III in the absorbance/reflectance mode.For HPLC, mobile phase consisting $0.02 \mathrm{M}$ ammonium acetate buffer: organic phase (where organic phase $\mathrm{MeOH}$ : $\mathrm{ACN}$ in ratio of $70: 30$ ) adjusted to $\mathrm{pH} 4.5$ with $0.6 \%$ GAA was prepared, filtered through $0.45 \mu \mathrm{m}$ membrane filter and degassed by an ultrasonic bath before each use. Best resolution and sensitivity of the method was obtained for SS, BH and ET at $275 \mathrm{~nm}$ at a flow rate of $1.0 \mathrm{~mL} \mathrm{~min} \mathrm{~m}^{-1}$ with gradient elution. The column was equilibrated for at least $30 \mathrm{~min}$ with the mobile phase flowing through the system. Each solution was injected in triplicate.

\section{Preparation of standard stock solutions}

Stock solutions of SS, BH and ET $\left(100 \mu \mathrm{g} \mathrm{m}^{-1}\right)$ were freshly prepared by dissolving in $\mathrm{MeOH}$ individually and stored at $2-8^{\circ} \mathrm{C}$ until used. The standard solutions were prepared by dilution of the stock standard solutions with $\mathrm{MeOH}$ (for HPTLC method) or with the mobile phase composition (for HPLC method) to obtain $10 \mu \mathrm{g} \mathrm{mL}^{-1}$. These solutions were used for optimization of proposed methods to reach the calibration curve for specified each method.Commercial formulations containing tablets of Eto-Salbetol (Batch Number-BTK0017, Kare Labs Pvt. Ltd., Goa , India), which were labeled to contain $2 \mathrm{mg}$ of SS, $8 \mathrm{mg}$ of BH and $200 \mathrm{mg}$ of ET per tablets were used for the study.

\section{Sample application}

In HPTLC, the samples were spotted as a band of $8 \mathrm{~mm}$ width on pre-coated silica gel aluminium backed plate 60F-254 with $200 \mu \mathrm{m}$ thickness. Application rate of $80 \mathrm{nl} \mathrm{s}^{-1}$ was employed and space between bands was $10 \mathrm{~mm}$. Linear ascending development was carried out in a twin trough glass chamber previously saturated with mobile phase for $20 \mathrm{~min}$. Densitometric scanning was performed on camag TLC scanner III in the absorbance/reflectance mode.In HPLC, the samples were filtered through a $0.2 \mu \mathrm{m}$ membrane filter using syringe filter holder. An aliquot of $20 \mu \mathrm{l}$ was injected with the help of Waters 2707 auto sampler.

\section{Optimization of chromatographic conditions}

HPTLC method: Chromatographic separations are significantly affected by mobile phase conditions, such as type and composition of organic modifiers therefore before selecting proper chromatographic conditions, numbers of preliminary trials were conducted with different combinations of different organic solvents, compositions, to obtain satisfactory retention factor, resolution, and other chromatographic parameters. From those experiments mobile phase combination of acetone: $\mathrm{MeOH}$ : formic acid (9: 3: 0.01 ) was found to be most suitable. Best resolution and sensitivity of the method for SS, BH and ET was detected at $275 \mathrm{~nm}$. Typical chromatogram with optimized condition gave sharp and resolved peaks with retention factor of $0.51,0.76$ and 0.85 for SS, ET and BH respectively. The developed chromatogram of $\mathrm{SS}, \mathrm{BH}$ and ET are shown in (Figure 2).

HPLC method: In order to achieve an optimum separation, following conditions were studied: (i) Mobile phase composition varied only in organic phase $(60 \% \mathrm{v} / \mathrm{v})$ keeping aqueous phase constant $(40 \% \mathrm{v} / \mathrm{v})$. Organic phase composition varied in different ratio of MeOH: ACN such as 50:50, 60:40 and 70:30 with fixed flow rate of $1.0 \mathrm{~mL} \min ^{-1}$ (ii) Change in $\mathrm{pH}$ such as $4.0,4.5$, and 5.0 with mobile phase composition 40:60 of 0.02 M ammonium acetate buffer: organic phase (MeOH: ACN in ratio of 70:30) (iii) Flow rate was varied such as $0.8,1.0$, and $1.2 \mathrm{~mL} \mathrm{~min}^{-1}$ with mobile phase composition in ratio of 40:60 of $0.02 \mathrm{M}$ ammonium acetate buffer: organic phase $(\mathrm{MeOH}$ : $\mathrm{ACN}$ in ratio of 70:30) and $\mathrm{pH}$ maintained at $\mathrm{pH}$ 4.5. Moreover, effects of three factors i.e. mobile phase composition, $\mathrm{pH}$ and flow rate were systematically addressed on system suitability parameters such as resolution, theoretical plates, retention time, capacity factor, separation factor, asymmetry, and HETP etc. After various trials of different chromatographic parameters, optimum mobile phase was found to be $0.02 \mathrm{M}$ ammonium acetate buffer: organic phase (where organic phase $\mathrm{MeOH}$ : $\mathrm{ACN}$ in ratio of 70:30) adjusted to $\mathrm{pH} 4.5$ with gradient elutionat flow rate of $1 \mathrm{~mL} \mathrm{~min}{ }^{-1}$. Best resolution and sensitivity of the method was obtained for SS, BH and ET at $275 \mathrm{~nm}$. Typical chromatogram with optimized condition gives sharp and symmetric peak with retention time of $2.8 \mathrm{~min}, 3.8 \mathrm{~min}$ and $13.2 \mathrm{~min}$ for ET, SS and $\mathrm{BH}$ respectively. Developed chromatogram of SS, BH and ET are shown in (Figure 3).

Validation of optimized method: After the chromatographic method had been optimized and developed, it must be validated; analytical method validation shows that the characteristics of the method satisfy the requirements of the application province. The 
Citation: Tyagi A, Sharma N, Mittal K, Mashru R, Bhardwaj T, et al. (2015) HPTLC-Densitometric and RP-HPLC Method Development and Validation for Determination of Salbutamol Sulphate, Bromhexine Hydrochloride and Etofylline in Tablet Dosage Forms. Pharm Anal Acta 6: 350. doi:10.4172/2153-2435.1000350

Page 3 of 9

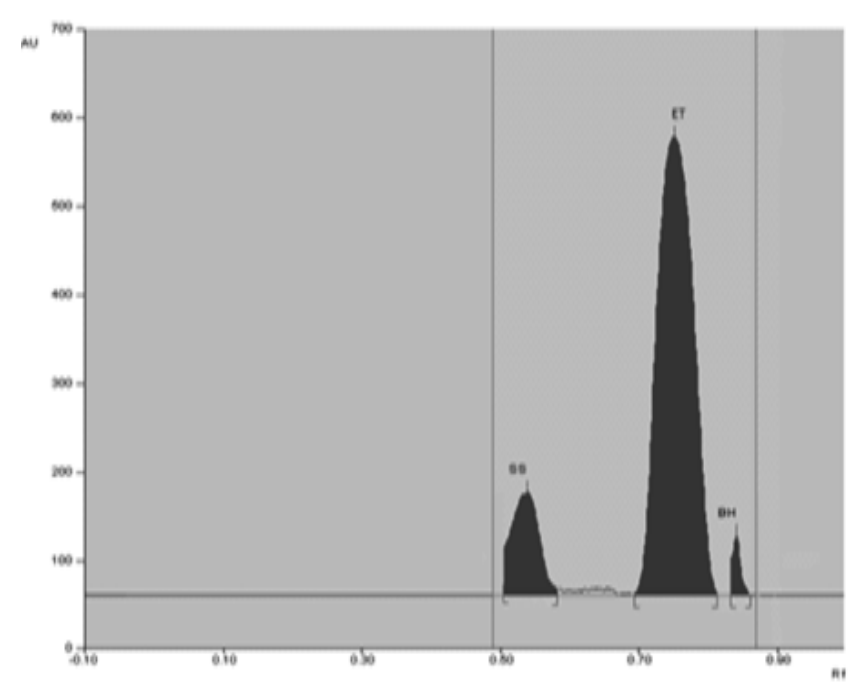

Figure 2: Chromatographic peaks of SS, ET and BH by optimized HPTLC method

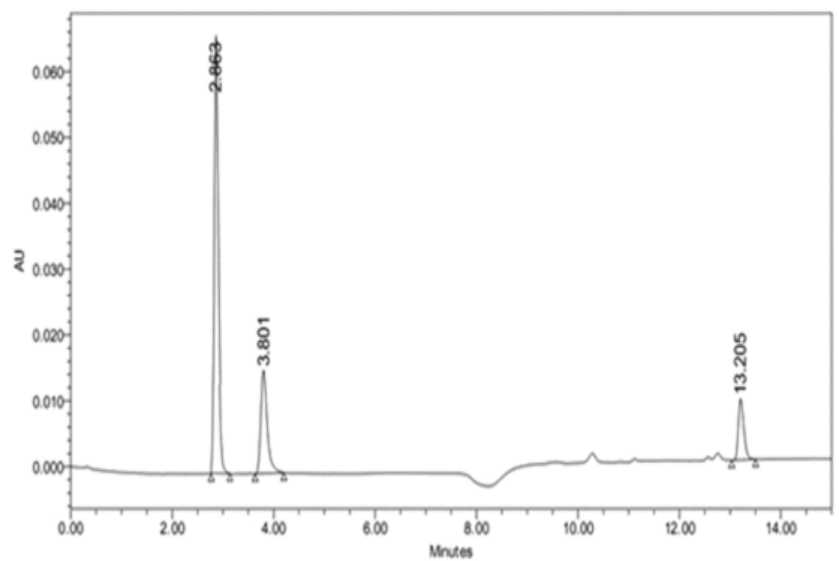

Figure 3: Chromatographic peaks of ET, SS and $\mathrm{BH}$ for optimized HPLC method.

proposed method was validated in the lime light of ICH guidelines for linearity, range, accuracy, precision, and limit of detection, limit of quantification, sensitivity, and recovery. Consequently, the following were performed.

Linearity: Linearity of an analytical procedure is its ability (within a given range) to obtain test results which are directly proportional to the concentration of analyte in the sample. Linearity was checked by diluting standard stock solution at six different concentrations. The calibration plot (peak area ratio of SS, BH and ET) was generated by replicate analysis $(n=3)$ at all concentration levels. Linearity was done by six different concentrations of SS, BH and ET in triplicate and calibration curve was plotted in specified range of 1-6 $\mu \mathrm{g} \mathrm{spot}^{-1}$ of SS and $\mathrm{BH}$ and 0.5-3.0 $\mu \mathrm{g} \mathrm{spot}^{-1}$ of ET for HPTLC and 1-32 $\mu \mathrm{gmL}^{-1}$ of SS and $\mathrm{BH}$ and $0.5-16 \mu \mathrm{gmL}^{-1}$ of ET for HPLC respectively. Calibration curve was plotted by replicate analysis at all concentration levels and linear relationship was evaluated using the least square method within Graph Pad Prism 5.01.0.
Precision and accuracy: The precision of the method was confirmed by repeatability and intermediate precision. It expresses the closeness of arrangement between a series of arrangements obtained from multiple sampling of the same homogeneous sample. The intermediate precision of the method was confirmed by intraday and interday analysis was repeated three times in the same day and on three successive days. The absorbance was determined and \% Relative Standard Deviation (RSD) also calculated.Accuracy expresses the arrangement between measured value and real value. To check the accuracy of the developed method and to study the interference of formulation excipients, analytical recovery experiments were carried out by using standard addition method in three different concentrations that is $80 \%, 100 \%$ and $120 \%$ of the standard drug. From the total amount of drug found, the percentage recovery was calculated. This procedure was repeated for three times for each concentration. Accuracy precision for the developed method was measured in terms of $\%$ RSD.

Specificity: This was ascertained by analyzing the $R_{f}$ values and spectra pattern of standard drug and marketed formulation. The peak purity of sample was determined by spectral comparison of sample peak at three different levels, viz. peak start (S), peak apex (M) and peak end (E) positions.

Sensitivity: Sensitivity of both the methods was determined by calculating LOB, Limit of detection (LOD) and Limit of Quantification (LOQ) using following equation:

$$
\begin{aligned}
& \mathrm{LOB}=1.645 \sigma / \mathrm{S} \\
& \mathrm{LOD}=3.3 \sigma / \mathrm{S} \\
& \mathrm{LOQ}=10 \sigma / \mathrm{S}
\end{aligned}
$$

Where $\sigma=$ Standard deviation of the response; $S=$ Slope of the calibration curve

Robustness: Robustness is small but deliberate change in samples under a variety of normal test conditions such as variation in solvent composition and wavelength. In present study, determination of SS, BH and ET were carried out by using change in mobile phase composition, mobile phase volume, and saturation time, activation time of precoated plates for HPTLC and change in mobile phase, Flow rate, $\mathrm{pH}$, and detection wavelength for HPLC. The deviations in the results of peak area were expressed as \% RSD.

Percentage purity: Twenty tablets were accurately powdered and weighed equivalent to $2 \mathrm{mg}$ of SS, $8 \mathrm{mg}$ of BH and $200 \mathrm{mg}$ of ET per tablets were used for the study and diluted up to $20 \mathrm{ml}$ with methanol. This dilution was used for spotting on stationary phase of method. Presence of SS, BH and ET in commercial formulations was confirmed by comparing its $\mathrm{R}_{\mathrm{f}}$ overlay (Figure 4 ). Purity of band of SS, BH and ET in sample (Figure 5) was determined by HPLC chromatogram by comparing UV absorption spectra at the start, middle, and end position of band with that of reference.

\section{Results and Discussion}

For the separation of non-polar and/or non-ionic substances normal phase chromatography can be used, while separation of nonionic as well as ion forming non-polar to medium polar substances reversedphase chromatography $(\mathrm{C} 8, \mathrm{C} 18)$ can be used. Thus, $\mathrm{SS}, \mathrm{BH}$ and ET can be satisfactorily separated by reversed phase chromatography. Majority of the ionizable pharmaceutical compounds can be very well separated on octadecylsilane reversed phase columns. Hence, octadecylsilane was selected. Sensitive, Rapid and novel HPLC method 
Citation: Tyagi A, Sharma N, Mittal K, Mashru R, Bhardwaj T, et al. (2015)HPTLC-Densitometric and RP-HPLC Method Development and Validation for Determination of Salbutamol Sulphate, Bromhexine Hydrochloride and Etofylline in Tablet Dosage Forms. Pharm Anal Acta 6: 350. doi:10.4172/2153-2435.1000350

Page 4 of 9

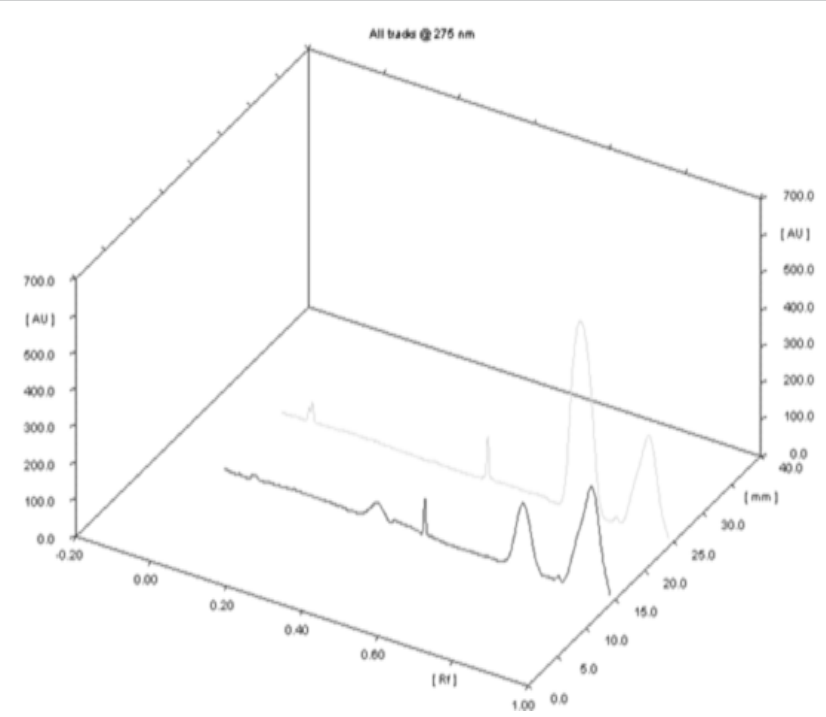

Figure 4: Overlay spectra of standard and marketed formulation for tertiary mixture of SS, ET and $\mathrm{BH}$.

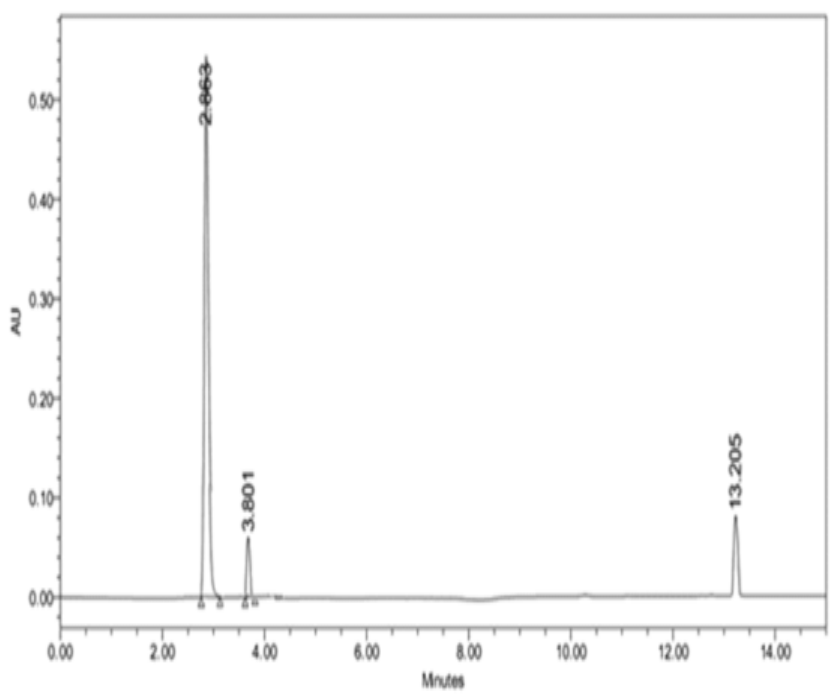

Figure 5: Chromatographic peaks of $\mathrm{ET}, \mathrm{SS}$ and $\mathrm{BH}$ in presence of excipients in tablet dosage form.

for determination of ternary mixture of drugs was optimized and validated.

\section{Optimization of chromatographic conditions}

Effect of mobile phase pH: With the aim of the optimization of mobile phase $\mathrm{pH}(4,4.5$ and 5$)$, the remaining two factors were kept constant, i.e. mobile phase composition (MeOH: ACN; 70:30, v/v)

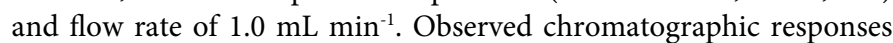
were plotted against respective $\mathrm{pH}$. As shown in the Figure 6, retention time increases with the increase in $\mathrm{pH}$ while asymmetry decreases. The number of theoretical plates as well as resolution of SS, BH and ET was maximum at $\mathrm{pH} 4.5$. Looking at the importance of the different chromatographic parameters, $\mathrm{pH} 4.5$ was found to be optimum. The dissociation constant (pKa) of SS is $10.3, \mathrm{BH}$ is 8.34 and ET is 13.39 at $\left(21-24^{\circ} \mathrm{C}\right)$. The asymmetry value decreases with increase in $\mathrm{pH}$.
At lower $\mathrm{pH}$ the ET will be carried out faster with mobile phase, however, due to higher unionized species. This result in tailing and hence increase in asymmetry value at lower $\mathrm{pH}$. At higher $\mathrm{pH}$ value, the ionized hydrophilic species are not much portioned with stationary phase and hence gives symmetric peak. The resolution was poor at $\mathrm{pH}$ 4.0, but was highest at $\mathrm{pH}$ 5.0. Similarly, the plate number (highest for higher retention time and smallest peak width) was highest at $\mathrm{pH}$ 5.0. Thus, the best chromatographic separation was achieved at $\mathrm{pH} 4.5$, and hence was considered to be optimum.

Effect of mobile phase composition: The effect of mobile phase composition (i.e. ratio of $\mathrm{MeOH}$ : $\mathrm{ACN}$ was studied at 50:50, 60:40 and $70: 30 \mathrm{v} / \mathrm{v}$ levels and the flow rate of $1.0 \mathrm{~mL} \mathrm{~min}^{-1}$ is shown in Figure 7. Minimum retention times of SS, BH and EZ were obtained at 70:30 $\mathrm{v} / \mathrm{v}$ level, which makes the method rapid, a one of the most desirable criteria. Though retention time was shorter, satisfactory resolution and asymmetry values were achieved. An adequate theoretical plates $(\sim 12000)$ is indicative of a good column performance As can be seen from Figure 7, the asymmetry was $>1.7$ at 50:50 and 60:40 v/v which indicates tailing of the peaks, but was $<1.9$ at $70: 30, \mathrm{v} / \mathrm{v}$.Similar findings were observed in the present study up to 50:50, v/v composition, but further increase in $\mathrm{ACN}$ content resulted in increased retention time in SS and $\mathrm{BH}$ and decreases for $\mathrm{BH}$. However, at 70:30, v/v composition, proper balance was attained and resulted in least retention time. The least asymmetry at 70:30 compared to other two compositions can be explained on the same basis. Plate number increased with increase in ACN composition in mobile phase. However, the asymmetry value at $60: 40 \mathrm{v} / \mathrm{v}$ was higher than that of at $70: 30 \mathrm{v} / \mathrm{v}$. These suggest that the increased plates at $70: 30, \mathrm{v} / \mathrm{v}$ was due to higher retention time value (even though it had greater peak width due to tailing). Further, acceptable resolution $(>2)$ was achieved at 70:30, v/v composition and so was considered to be optimum.

Effect of mobile phase flow rate: From Figure 8, it can be observed that theoretical plates were highest at flow rate of $1.0 \mathrm{~mL} \mathrm{~min}{ }^{-1}$ with asymmetry of less than 1.2. The change in flow rate had no significant effect on resolution. While retention time decrease as the flow rate increased with poor plates and higher asymmetry. Further, acceptable resolution $(>2)$ with plates was achieved at $1.0 \mathrm{~mL} \mathrm{~min}^{-1}$ and so was considered to be optimum.

Proposed chromatographic method: The developed chromatogram SS, BH and ET gave sharp UV absorbance peak at $275 \mathrm{~nm}$ with mobile phase containing acetone: $\mathrm{MeOH}$ : formic acid (9:3:0.01) with $R_{f}$ values $0.51,0.76$ for SS, ET and 0.85 for $B H$ respectively for HPTLC. Looking at the different chromatographic parameters during the method development, the finally recommended mobile phase consisted of $\mathrm{MeOH}$ : ACN $0.02 \mathrm{M}$ of 70:30, v/v adjusted to $\mathrm{pH}$ 4.5. The best resolution and sensitivity of the method was obtained at $275 \mathrm{~nm}$

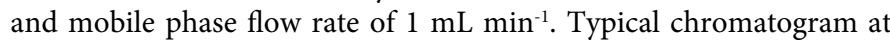
the optimized condition gave sharp and symmetric peak with retention time of 2.8, 3.8 and 13.2 min for ET, SSand BH respectively.

\section{Validation of the proposed method}

Calibration curve (linearity): Calibration curve (peak area ratio of SS, BH and ETconcentration) in mobile phase. The chromatographic responses were found to be linear over an analytical range of 1-6 $\mu \mathrm{g}$ spot ${ }^{1}$ of SS and BH and $0.5-3.0 \mu$ spot $^{-1}$ of ET with a correlation coefficient of 0.998 for SS and 0.997 for BH and ET respectively for HPTLC and Relationship between the concentration of standard solutions and peak response was linear within the concentration range of $1-32 \mu \mathrm{gmL}^{-1}$ of $\mathrm{SS}$ and $\mathrm{BH}$ and $0.5-16 \mu \mathrm{gmL}^{-1}$ of ET with correlation coefficient equals 
Citation: Tyagi A, Sharma N, Mittal K, Mashru R, Bhardwaj T, et al. (2015)HPTLC-Densitometric and RP-HPLC Method Development and Validation for Determination of Salbutamol Sulphate, Bromhexine Hydrochloride and Etofylline in Tablet Dosage Forms. Pharm Anal Acta 6: 350. doi:10.4172/2153-2435.1000350

Page 5 of 9

(a).

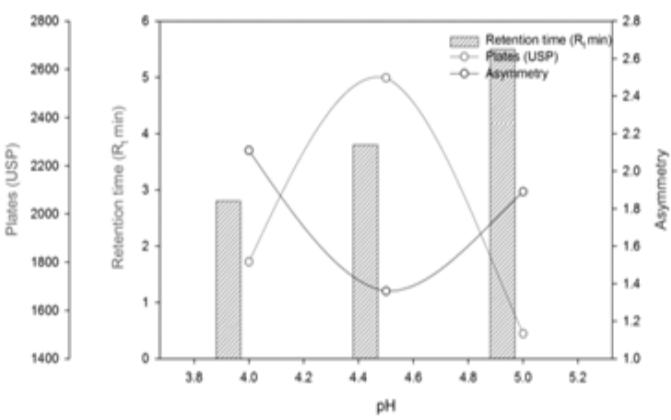

(b).

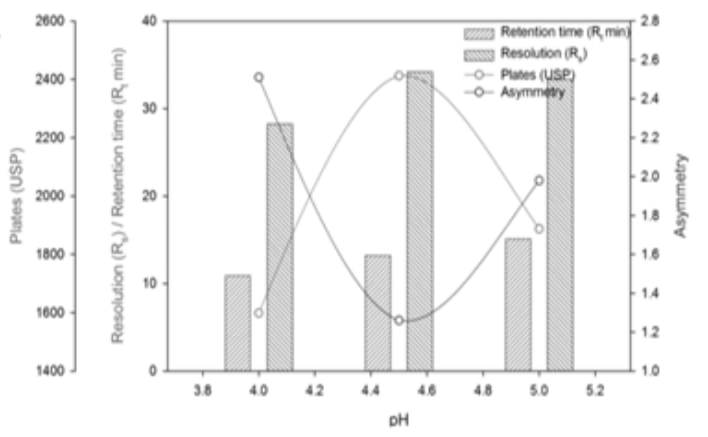

(c).

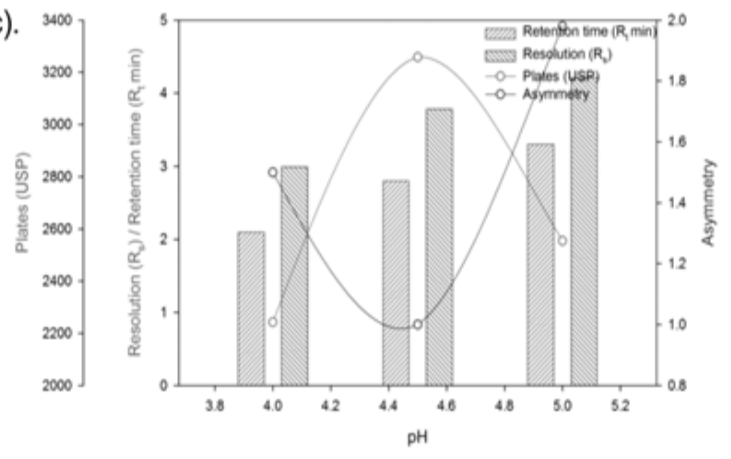

Figure 6: Effect of mobile phase $\mathrm{pH}(4,4.5$ and 5$)$ at mobile phase composition of 70:30 (MeOH:ACN v/v) and flow rate of $1.0 \mathrm{~mL} \mathrm{~min}^{-1} ;$ (a) for S.S. (b) for B.H. and (c) for E.T.
0.999 for HPLC and found to be quite satisfactory and reproducible with time. The linear regression equation was calculated by the least squares method using Graph Pad Prism 5.01.0 program. The variance of slope and intercept were reported in Table 1 and 2. This shows that the intercept is not significantly different from zero, indicating no interference in the estimations. Further the slope and intercept were within the confidence interval.

Accuracy and precision: Accuracy data in the present study is performed by three different combination of marketed formulations ranged from 98.75 to $99.99 \%$ for HPTLC and 98.75 to 99.96 for HPLC indicates that there was no interference from excipients components. Interday as well as intraday replicates of SS, BH and ET gave an RSD below 2.0 (should be less than 2 according to Center for Drug Evaluation and Research (CDER) guidance for analytical method validation), revealed that the proposed method is highly precise. Accuracy of the method was evaluated by using t-test at four concentration levels including the lowest quantifiable level. The $t$-values obtained for different spiked amount of SS, BH and ET. The t-value required for significance at $5 \%$ level at 5 degrees of freedom is 2.57 , and the obtained values were well below this value. Thus no significant difference was observed between the amounts of drug added and recovered. Overall, the data summarized in Table 3 and 4 , enables the conclusion that an excellent accuracy and high precision was obtained.

Robustness: The \% RSD was found to be less than $1 \%$ for the method, which support the effectiveness and usefulness of the method respectively and percentage purity of SS, BH and ET were found to be $99.41 \pm 1.09 \% \mathrm{w} / \mathrm{w}, 98.36 \pm 0.33 \% \mathrm{w} / \mathrm{w}$ and $98.89 \pm 0.04 \% \mathrm{w} / \mathrm{w}$ respectively for HPTLC and $99.93 \pm 1.33 \% \mathrm{w} / \mathrm{w}, 99.48 \pm 0.57 \% \mathrm{w} / \mathrm{w}$ and $97.34 \pm 0.02 \% \mathrm{w} / \mathrm{w}$ respectively shown in table for HPLC. Robustness studies for both methods are shown in Tables 5 and 6 .

Sensitivity: The LOD and LOQ for SS, BH and ET were found to be 100, 200 and 10 and 330, 660 and 33 ngmL $^{-1}$ for HPTLC and 150, 200 and 10 and 495, 660 and 49 for HPLC respectively. The present method was selective enough to and can be applied for simultaneously analyze SS, BH and ET in marketed pharmaceutical formulation, its sensitivity was found to be adequate for assay and dissolution test of tablets for the estimation of title drugs in their commercial samples.

Specificity: Specificity is the extent to which the procedure applies to analyte of interest and is checked by examining the formulation samples for any interfering peaks. The specificity of the method was

\begin{tabular}{|c|c|c|c|}
\hline Parameters & SS & $\mathrm{BH}$ & ET \\
\hline Absorption maxima $(\mathrm{nm})$ & 275 & 275 & 275 \\
\hline Linearity range $\left(\mu \mathrm{g} \mathrm{spot}^{-1}\right)$ & $1-6$ & $1-6$ & $0.5-3.0$ \\
\hline Coefficient of determination $\left(r^{2}\right)$ & 0.998 & 0.997 & 0.998 \\
\hline Correlation coefficient ( $r$ ) & 0.999 & 0.999 & 0.999 \\
\hline Regression equation $\left(\mathrm{Y}^{\mathrm{a}}\right)$ & $Y=488.2 x+754.7$ & $Y=292.3 x+116.7$ & $Y=5291 x+3476$ \\
\hline Slope (m) & 488.2 & 292.3 & 5291 \\
\hline $\mathrm{t}_{\mathrm{cal}}^{\mathrm{m}}$ & 1.3234 & 1.2857 & 0.1323 \\
\hline Confidence interval ${ }^{\mathrm{m}}$ & $488.2 \pm 21.67$ & $292.3 \pm 3.99$ & $5291 \pm 100.62$ \\
\hline Intercept (c) & 754.7 & 116.7 & 3476 \\
\hline $\mathrm{t}_{\mathrm{cal}}^{\mathrm{m}}$ & 0.5249 & 0.6368 & 1.4692 \\
\hline Confidence interval ${ }^{m}$ & $754.7 \pm 59.23$ & $116.7 \pm 19.62$ & $3476 \pm 103.52$ \\
\hline Limit of detection LOD, (ng) & 100 & 200 & 10 \\
\hline Limit of quantification LOQ (ng) & 330 & 660 & 33 \\
\hline $\begin{array}{c}\text { Precision, Intra-day (\%RSD) } \\
\text { Inter-day (\%RSD) }\end{array}$ & $\begin{array}{l}0.79 \\
0.53\end{array}$ & $\begin{array}{l}0.94 \\
1.21\end{array}$ & $\begin{array}{l}0.31 \\
0.26\end{array}$ \\
\hline
\end{tabular}

Table 1:Validation parameters of HPTLC method for SS, BH and ET 
Citation: Tyagi A, Sharma N, Mittal K, Mashru R, Bhardwaj T, et al. (2015)HPTLC-Densitometric and RP-HPLC Method Development and Validation for Determination of Salbutamol Sulphate, Bromhexine Hydrochloride and Etofylline in Tablet Dosage Forms. Pharm Anal Acta 6: 350 doi:10.4172/2153-2435.1000350

Page 6 of 9

\begin{tabular}{|c|c|c|c|}
\hline Parameters & SS & $\mathrm{BH}$ & ET \\
\hline Absorption maxima (nm) & 275 & 275 & 275 \\
\hline Linearity range $\left(\mu \mathrm{g} \mathrm{mL}^{-1}\right)$ & $1-32$ & $1-32$ & $0.5-16$ \\
\hline Coefficient of determination $\left(\mathrm{r}^{2}\right)$ & 0.997 & 0.998 & 0.998 \\
\hline Correlation coefficient $(r)$ & 0.999 & 0.999 & 0.999 \\
\hline Regression equation $\left(Y^{a}\right)$ & $Y=4253 x-2508$ & $Y=16462 x-403.9$ & $Y=25609 x-3524$ \\
\hline Slope (m) & 4253 & 16462 & 25609 \\
\hline $\mathrm{t}_{\mathrm{cal}}^{\mathrm{m}}$ & 1.5241 & 1.2872 & 0.5341 \\
\hline Confidence interval ${ }^{\mathrm{m}}$ & $4253 \pm 91.67$ & $16462 \pm 59.77$ & $25609 \pm 274.62$ \\
\hline Intercept (c) & -2508 & -403.9 & -3524 \\
\hline $\mathrm{t}_{\mathrm{cal}}^{\mathrm{m}}$ & 0.0007 & 0.0162 & 0.0100 \\
\hline Confidence interval ${ }^{\mathrm{m}}$ & $-2508 \pm 649.06$ & $-403.9 \pm 544.72$ & $-3524 \pm 923.37$ \\
\hline LOB $\left(\mu \mathrm{g} \mathrm{mL}^{-1}\right)$ & 0.0455 & 0.0606 & 0.0045 \\
\hline LOD $\left(\mu \mathrm{g} \mathrm{mL}^{-1}\right)$ & 0.1500 & 0.2000 & 0.0150 \\
\hline $\mathrm{LOQ}\left(\mu \mathrm{g} \mathrm{mL} \mathrm{L}^{-1}\right)$ & 0.4950 & 0.6600 & 0.0495 \\
\hline $\begin{array}{c}\text { Precision, Intra-day (\%RSD) } \\
\text { Inter-day (\%RSD) }\end{array}$ & $\begin{array}{l}0.72 \\
1.17\end{array}$ & $\begin{array}{l}0.45 \\
0.89\end{array}$ & $\begin{array}{l}0.30 \\
0.52\end{array}$ \\
\hline
\end{tabular}

Table 2: Validation parameters for RP-HPLC method of SS, BH and ET.

(a).

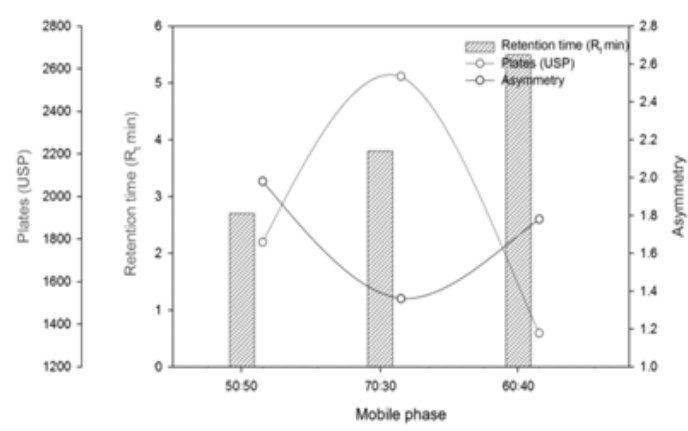

(b).

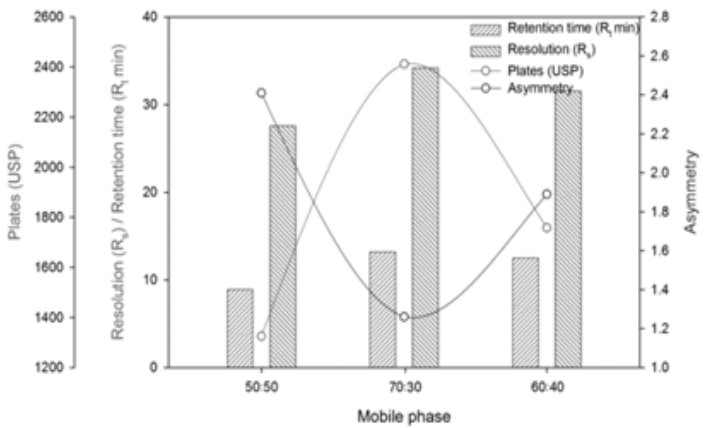

(c).

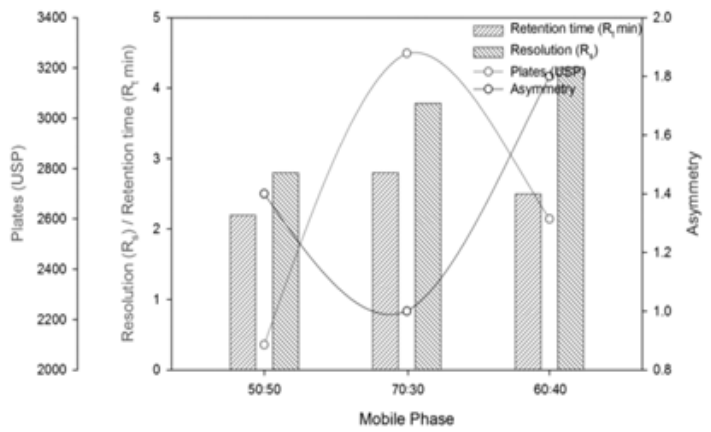

Figure 7: Effect of mobile phase composition (50:50,70:30 and 60:40 MeOH:ACN $\mathrm{v} / \mathrm{v}$ ) at mobile phase ph 4.5 and flow rate of $1.0 \mathrm{~mL} \mathrm{~min}^{-1}$; (a) for S.S. (b) for B.H. and (c) for E.T. (a).

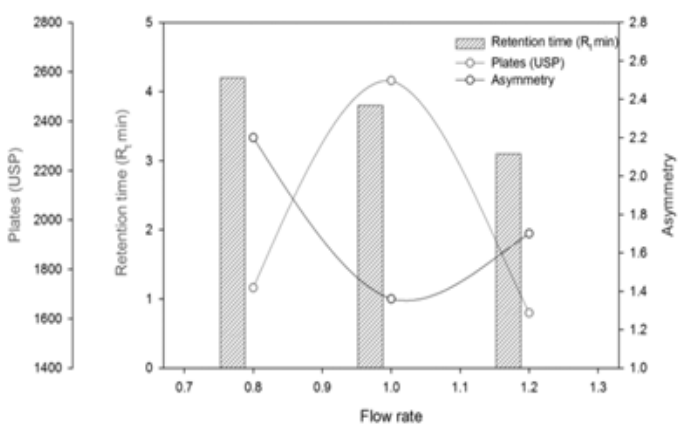

(b).

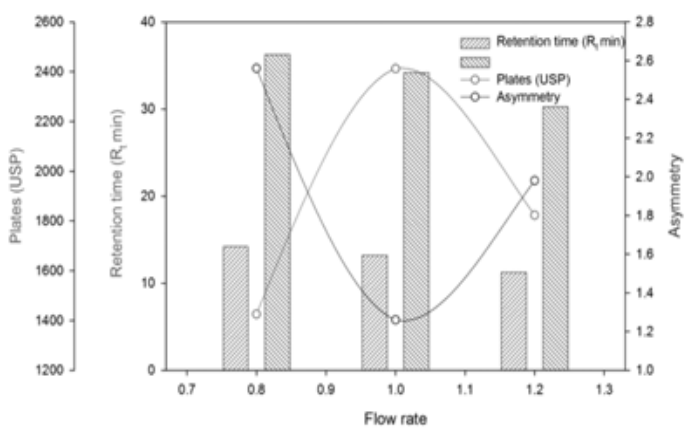

(c).

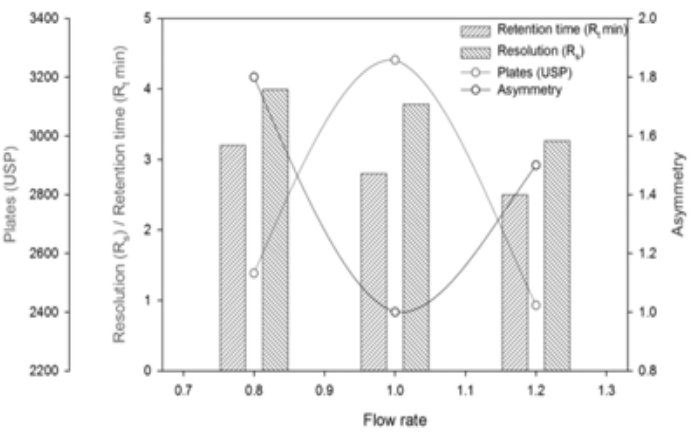

Figure 8: Effect of flow rate $\left(0.8,1.0\right.$, and $\left.1.2 \mathrm{~mL} \mathrm{~min}^{-1}\right)$ at mobile phase $\mathrm{pH} 4.5$ and mobile phase composition 70:30 MeOH:ACN v/v (a) for S.S. (b) for B.H. and (c) for E.T. 
Citation: Tyagi A, Sharma N, Mittal K, Mashru R, Bhardwaj T, et al. (2015) HPTLC-Densitometric and RP-HPLC Method Development and Validation for Determination of Salbutamol Sulphate, Bromhexine Hydrochloride and Etofylline in Tablet Dosage Forms. Pharm Anal Acta 6: 350. doi:10.4172/2153-2435.1000350

Page 7 of 9

evaluated with regard to interference due to presence of excipients. The excipients used in formulation did not interfere with the SS, BH and ET peaks and thus the method is specific.

System suitability: System suitability tests, an integral part of a chromatographic analysis are used to verify that the resolution and reproducibility of the chromatographic system are adequate for the analysis [24]. A system suitability test according to USP was performed on the chromatograms obtained from standard and test solutions to check different above mentioned parameters and the results obtained from six replicate injections of the standard solution are summarized in the Table 7.

Formulation analysis: The proposed methods were applied to the determination of SS, BH and ET in commercial tablets. Satisfactory results were obtained for tertiary mixture of drugs and were in good agreement with the label claims (Table 8). Moreover, to check the validity of the proposed methods, the standard addition method was applied by adding SS, BH and ET to the previously analyzed tablets. The recovery of each drug was calculated by comparing the concentration obtained from the spiked mixtures with those of the pure drug. The results of analysis of the commercial tablets and the recovery study (standard addition method) of three drugs (Tables 3 and 4) suggested that there is no interference from any excipients, which are present in tablets.

Statistical analysis: A statistical comparison of the results was performed with regard to accuracy and precision using Student's t-test at a 95\% confidence level (Tables 3 and 4). The t-values obtained for different spiked amount of SS, BH and ET. The t-value required for significance at $5 \%$ level at 5 degrees of freedom is 2.57 , and the obtained values were well below this value. Thus no significant difference between the proposed was observed between the amounts of drug added and recovered with regard to accuracy and precision. The descriptive stastical analyses were also applied on the HPTLC and HPLC methods (Tables 9 and 10) which further confirm the sensitivity and accuracy of the proposed method for the estimation of SS, BH and ET in commercial formulations.

\section{Conclusion}

Accurate results for determination of individual drug in combination of single pharmaceutical dosages form by applying HPTLC and HPLC method were achieved. The proposed HPTLC and HPLC methods provide simple, accurate, and reproducible quantitative analysis for simultaneous determination SS, BH and ET in tablets. The HPLC method is more rapid in terms of sensitivity and accuracy than HPTLC. The proposed validated methods are good alternative for the simultaneous estimation of tertiary mixture in pharmaceutical formulation. This method has been found to be suitable for the successful simultaneous estimation of the SS, BH and ET in the formulation. This method can also be applied for the estimation of these drugs in other combination or can also be used for the estimation of these drugs individually.

\section{References}

\begin{tabular}{|c|c|c|c|}
\hline Parameters & SS & $\mathrm{BH}$ & ET \\
\hline Absorption maxima (nm) & 275 & 275 & 275 \\
\hline Linearity range $\left(\mu \mathrm{g} \mathrm{spot}^{-1}\right)$ & $1-6$ & $1-6$ & $0.5-3.0$ \\
\hline Coefficient of determination $\left(r^{2}\right)$ & 0.998 & 0.997 & 0.998 \\
\hline Correlation coefficient ( $r$ ) & 0.999 & 0.999 & 0.999 \\
\hline Regression equation $\left(\mathrm{Y}^{\mathrm{a}}\right)$ & $Y=488.2 x+754.7$ & $Y=292.3 x+116.7$ & $Y=5291 x+3476$ \\
\hline Slope (m) & 488.2 & 292.3 & 5291 \\
\hline $\mathrm{t}_{\mathrm{cal}}^{\mathrm{m}}$ & 1.3234 & 1.2857 & 0.1323 \\
\hline Confidence interval $^{\mathrm{m}}$ & $488.2 \pm 21.67$ & $292.3 \pm 3.99$ & $5291 \pm 100.62$ \\
\hline Intercept (c) & 754.7 & 116.7 & 3476 \\
\hline $\mathrm{t}_{\mathrm{cal}}^{\mathrm{m}}$ & 0.5249 & 0.6368 & 1.4692 \\
\hline Confidence interval $^{\mathrm{m}}$ & $754.7 \pm 59.23$ & $116.7 \pm 19.62$ & $3476 \pm 103.52$ \\
\hline Limit of detection LOD, (ng) & 100 & 200 & 10 \\
\hline Limit of quantification LOQ (ng) & 330 & 660 & 33 \\
\hline $\begin{array}{l}\text { Precision, Intra-day (\%RSD) } \\
\text { Inter-day (\%RSD) }\end{array}$ & $\begin{array}{l}0.79 \\
0.53\end{array}$ & $\begin{array}{l}0.94 \\
1.21\end{array}$ & $\begin{array}{l}0.31 \\
0.26\end{array}$ \\
\hline
\end{tabular}

Table 3: Results of recovery study of SS, BH and ET by HPTLC Method.

\begin{tabular}{|c|c|c|c|c|c|c|c|c|c|c|c|c|c|c|c|c|c|c|c|c|}
\hline \multicolumn{3}{|c|}{ Amount Spike } & \multicolumn{3}{|c|}{ Amount found } & \multicolumn{3}{|c|}{ SD } & \multicolumn{3}{|c|}{ \%RSD } & \multicolumn{3}{|c|}{ Recovery } & \multicolumn{3}{|c|}{$t_{\text {cal }}$} & \multicolumn{3}{|c|}{$\mathrm{Cl}$} \\
\hline SS & $\mathrm{BH}$ & ET & SS & $\mathrm{BH}$ & ET & SS & $\mathrm{BH}$ & ET & SS & $\mathrm{BH}$ & ET & SS & $\mathrm{BH}$ & ET & SS & $\mathrm{BH}$ & ET & SS & $\mathrm{BH}$ & ET \\
\hline \multicolumn{21}{|c|}{ Intra-day $(n=3)$} \\
\hline 1.6 & 6.4 & 160 & 1.59 & 6.39 & 159.54 & 0.0058 & 0.0153 & 0.7427 & 0.3616 & 0.2389 & 0.4655 & 99.79 & 99.90 & 99.71 & 1.00 & 0.76 & 1.06 & 0.0086 & 0.0227 & 1.1045 \\
\hline 2.0 & 8.0 & 200 & 1.99 & 7.99 & 199.39 & 0.0100 & 0.0153 & 0.7396 & 0.5025 & 0.1913 & 0.3709 & 99.50 & 99.83 & 99.69 & 1.72 & 1.51 & 1.43 & 0.0149 & 0.0227 & 1.0999 \\
\hline 2.4 & 9.6 & 240 & 2.38 & 9.59 & 239.58 & 0.0153 & 0.0100 & 0.8145 & 0.6409 & 0.1043 & 0.3400 & 99.31 & 99.90 & 99.82 & 1.88 & 1.73 & 0.90 & 0.0227 & 0.0149 & 1.2112 \\
\hline \multicolumn{21}{|c|}{ Inter-day $(n=6)$} \\
\hline 1.6 & 6.4 & 160 & 1.59 & 6.38 & 159.54 & 0.0141 & 0.0207 & 0.9247 & 0.89 & 0.3236 & 0.5796 & 99.38 & 99.74 & 99.71 & 1.72 & 1.97 & 1.21 & 0.0210 & 0.0307 & 1.3752 \\
\hline 2.0 & 8.0 & 200 & 1.98 & 7.99 & 199.48 & 0.0137 & 0.0137 & 1.3012 & 0.69 & 0.1711 & 0.6523 & 99.17 & 99.83 & 99.74 & 2.96 & 2.39 & 0.97 & 0.0203 & 0.0203 & 1.9351 \\
\hline 2.4 & 9.6 & 240 & 2.38 & 9.57 & 239.83 & 0.0147 & 0.0279 & 1.0394 & 0.62 & 0.2907 & 0.4334 & 99.51 & 99.88 & 99.93 & 1.93 & 1.02 & 0.40 & 0.0219 & 0.0414 & 1.5458 \\
\hline
\end{tabular}

Table 4: Results of recovery study of SS, BH and ET by HPLC Method. 
Citation: Tyagi A, Sharma N, Mittal K, Mashru R, Bhardwaj T, et al. (2015)HPTLC-Densitometric and RP-HPLC Method Development and Validation for Determination of Salbutamol Sulphate, Bromhexine Hydrochloride and Etofylline in Tablet Dosage Forms. Pharm Anal Acta 6: 350. doi:10.4172/2153-2435.1000350

Page 8 of 9

\begin{tabular}{|c|c|c|c|c|c|c|c|c|c|c|}
\hline \multirow[t]{2}{*}{ Parameters } & \multirow[t]{2}{*}{ Alterations } & \multicolumn{2}{|c|}{$\begin{array}{l}\text { \%RSD for Retention } \\
\text { factor }(n=6)\end{array}$} & \multirow[b]{2}{*}{ ET } & \multicolumn{2}{|c|}{$\%$ RSD for Area $(n=6)$} & \multirow[b]{2}{*}{ ET } & \multicolumn{2}{|c|}{ \%RSD for Assay $(n=6)$} & \multirow[b]{2}{*}{ ET } \\
\hline & & SS & $\mathrm{BH}$ & & SS & $\mathrm{BH}$ & & SS & $\mathrm{BH}$ & \\
\hline \multirow{3}{*}{$\begin{array}{l}\text { Mobile phase } \\
\text { composition }\end{array}$} & $-2 \%$ & 0.1121 & 0.2622 & 0.2739 & 0.2969 & 0.2787 & 0.2753 & 0.1462 & 0.2749 & 0.3119 \\
\hline & Normal & 0.1289 & 0.1664 & 0.2642 & 0.3180 & 0.2761 & 0.2891 & 0.1841 & 0.3188 & 0.3992 \\
\hline & $+2 \%$ & 0.1379 & 0.1785 & 0.1989 & 0.2984 & 0.2835 & 0.2342 & 0.2101 & 0.3218 & 0.3861 \\
\hline \multirow{3}{*}{ Mobile phase volume } & -2.0unit & 0.3121 & 0.2963 & 0.4561 & 0.1623 & 0.3429 & 0.3041 & 0.2572 & 0.3176 & 0.4172 \\
\hline & Normal & 0.3462 & 0.2784 & 0.6439 & 0.1343 & 0.4119 & 0.2801 & 0.3442 & 0.3219 & 0.4974 \\
\hline & +2.0unit & 0.3429 & 0.3072 & 0.4534 & 0.1587 & 0.3741 & 0.2420 & 0.3596 & 0.4281 & 0.4990 \\
\hline \multirow{3}{*}{ Saturation time } & -5.0unit & 0.2943 & 0.3257 & 0.4422 & 0.2039 & 0.4752 & 0.2991 & 0.3186 & 0.4376 & 0.5469 \\
\hline & Normal & 0.2845 & 0.3724 & 0.4753 & 0.2205 & 0.4969 & 0.3527 & 0.2792 & 0.4810 & 0.5670 \\
\hline & +5.0unit & 0.3108 & 0.3572 & 0.4631 & 0.2265 & 0.5264 & 0.4124 & 0.3126 & 0.5292 & 0.5911 \\
\hline \multirow{3}{*}{$\begin{array}{l}\text { Activation time of pre- } \\
\text { coated plates }\end{array}$} & -2.0unit & 0.2191 & 0.2652 & 0.1540 & 0.1872 & 0.2719 & 0.1041 & 0.2389 & 0.2110 & 0.4002 \\
\hline & Normal & 0.2349 & 0.2743 & 0.2439 & 0.1943 & 0.3287 & 0.2671 & 0.3219 & 0.2397 & 0.4784 \\
\hline & +2.0unit & 0.2429 & 0.3017 & 0.3576 & 0.2580 & 0.3551 & 0.2299 & 0.3109 & 0.2639 & 0.4892 \\
\hline \multirow{3}{*}{ Detection wavelength } & -0.4unit & 0.0132 & 0.4873 & 0.2682 & 0.4129 & 0.3758 & 0.4944 & 0.4480 & 0.4632 & 0.3481 \\
\hline & Normal & 0.1201 & 0.5621 & 0.2872 & 0.4483 & 0.3432 & 0.4130 & 0.5702 & 0.4671 & 0.3630 \\
\hline & +0.4unit & 0.2091 & 0.5892 & 0.2249 & 0.4882 & 0.3774 & 0.3873 & 0.4165 & 0.4610 & 0.3979 \\
\hline
\end{tabular}

Table 5: Robustness parameter of SS, BH and ET studied for HPTLC method.

\begin{tabular}{|c|c|c|c|c|c|c|c|c|c|c|}
\hline \multirow[t]{2}{*}{ Parameters } & \multirow[t]{2}{*}{ Alterations } & \multicolumn{2}{|c|}{$\begin{array}{l}\text { \%RSD for Retention time } \\
\qquad(n=6)\end{array}$} & \multirow[b]{2}{*}{ ET } & \multicolumn{2}{|c|}{$\% R S D$ for Area $(n=6)$} & \multirow[b]{2}{*}{ ET } & \multicolumn{2}{|c|}{$\%$ RSD for Assay $(n=6)$} & \multirow[b]{2}{*}{ ET } \\
\hline & & SS & $\mathrm{BH}$ & & SS & $\mathrm{BH}$ & & SS & $\mathrm{BH}$ & \\
\hline \multirow{3}{*}{ Mobile phase } & $-2 \%$ & 0.2143 & 0.2812 & 0.2018 & 0.2942 & 0.3782 & 0.4871 & 0.2431 & 0.3872 & 0.4321 \\
\hline & Normal & 0.2452 & 0.1466 & 0.2167 & 0.2180 & 0.3764 & 0.4813 & 0.2761 & 0.4286 & 0.4982 \\
\hline & $+2 \%$ & 0.1462 & 0.1676 & 0.1972 & 0.2943 & 0.3842 & 0.4319 & 0.3108 & 0.4202 & 0.4874 \\
\hline \multirow{3}{*}{ Flow rate } & $-10 \%$ & 0.3113 & 0.4961 & 0.4563 & 0.1278 & 0.4411 & 0.3042 & 0.4532 & 0.4022 & 0.5487 \\
\hline & Normal & 0.3871 & 0.5786 & 0.6431 & 0.1132 & 0.5039 & 0.1892 & 0.5431 & 0.4135 & 0.5982 \\
\hline & $+10 \%$ & 0.3217 & 0.6071 & 0.4532 & 0.1484 & 0.4988 & 0.2791 & 0.4596 & 0.5014 & 0.4983 \\
\hline \multirow{3}{*}{$\mathrm{pH}$} & -0.2 unit & 0.3924 & 0.4254 & 0.5432 & 0.2097 & 0.4373 & 0.3921 & 0.3216 & 0.6165 & 0.6732 \\
\hline & Normal & 0.3854 & 0.4711 & 0.5761 & 0.2243 & 0.4828 & 0.4506 & 0.2988 & 0.6746 & 0.6178 \\
\hline & +0.2unit & 0.4116 & 0.4582 & 0.5629 & 0.2198 & 0.5498 & 0.5106 & 0.3116 & 0.5153 & 0.6988 \\
\hline \multirow{3}{*}{ Detection wavelength } & -0.2 unit & 0.3132 & 0.6464 & 0.2678 & 0.4173 & 0.5876 & 0.2984 & 0.5473 & 0.3628 & 0.2756 \\
\hline & Normal & 0.3201 & 0.6919 & 0.2891 & 0.4442 & 0.5342 & 0.2135 & 0.6759 & 0.3684 & 0.2431 \\
\hline & +0.2 unit & 0.3091 & 0.5867 & 0.2289 & 0.4892 & 0.5982 & 0.2007 & 0.5192 & 0.3651 & 0.2998 \\
\hline
\end{tabular}

Table 6: Robustness parameter of SS, BH and ET studied for HPLC method.

\begin{tabular}{|c|c|c|c|}
\hline SST Parameters & ET & SS \\
\hline Capacity factor $(k)$ & 8.51 & 11.66 \\
\hline Asymmetry $\left(A_{s}\right)$ & 1 & 1.7 \\
\hline Tailing factor $\left(T_{f}\right)$ & 1 & 1.36 \\
\hline HETP $(m)$ & 0.0215 & 0.0066 & 1.5 \\
\hline Separation factor $(\alpha)$ & 8.93 & - & 0.0034 \\
\hline Resolution $\left(R_{s}\right)$ & 3.78 & 45.19 \\
\hline Plate Count & 3258.13 & 2564.41 \\
\hline
\end{tabular}

Table 7: System suitability parameters of SS, BH and ET for RP-HPLC method.

\begin{tabular}{|l|c|c|c|c|}
\hline Formulation & Method & \% Labeled claim obtained for SS & \% Labeled claim obtained for BH & \% Labeled claim obtained for ET \\
\hline \multirow{2}{*}{ Eto-Salbetol } & HPTLC & $99.4091 \pm 1.0956$ & $98.3579 \pm 0.3252$ \\
\cline { 2 - 4 } & HPLC & $99.93 \pm 1.33$ & $99.48 \pm 0.57$ & $97.34 \pm 0.02$ \\
\hline
\end{tabular}

Table 8: Percent purity of SS, BH and ET in tablet dosage forms by HPTLC method. 
Citation: Tyagi A, Sharma N, Mittal K, Mashru R, Bhardwaj T, et al. (2015)HPTLC-Densitometric and RP-HPLC Method Development and Validation for Determination of Salbutamol Sulphate, Bromhexine Hydrochloride and Etofylline in Tablet Dosage Forms. Pharm Anal Acta 6: 350. doi:10.4172/2153-2435.1000350

Page 9 of 9

\begin{tabular}{|c|c|c|c|}
\hline Parameters & SS & BH & ET \\
\hline Maximum & 99.930 & 99.960 & 99.990 \\
\hline Minimum & 98.750 & 99.600 & 99.550 \\
\hline Median & 99.555 & 99.675 & 99.840 \\
\hline Mean & 99.473 & 99.745 & 99.825 \\
\hline S.D. & 0.405 & 0.159 & 0.166 \\
\hline S.E. & 0.165 & 0.065 & 0.068 \\
\hline Cl of mean & 0.425 & 0.167 & 0.174 \\
\hline Skewness & -1.217 & 0.779 & -0.836 \\
\hline Kurtosis & 2.108 & -1.854 & 0.269 \\
\hline K-S distribution & 0.242 & 0.254 & 0.160 \\
\hline K-S probability & 0.310 & 0.254 & 0.723 \\
\hline SWilk W & 0.904 & 0.816 & 0.920 \\
\hline SWilk Probability & 0.398 & 0.082 & 0.507 \\
\hline
\end{tabular}

Table 9: Discriptive statistical analysis parameters of SS, BH and ET on HPTLC accuracy results

\begin{tabular}{|c|c|c|c|}
\hline Parameters & SS & BH & ET \\
\hline Maximum & 99.790 & 99.900 & 99.930 \\
\hline Minimum & 99.170 & 99.740 & 99.690 \\
\hline Median & 99.440 & 99.855 & 99.725 \\
\hline Mean & 99.443 & 99.847 & 99.767 \\
\hline S.D. & 0.212 & 0.061 & 0.092 \\
\hline S.E. & 0.087 & 0.025 & 0.038 \\
\hline Cl of mean & 0.222 & 0.064 & 0.097 \\
\hline Skewness & 0.603 & -1.154 & 1.405 \\
\hline Kurtosis & 0.839 & 1.082 & 1.251 \\
\hline K-S distribution & 0.210 & 0.226 & 0.280 \\
\hline K-S probability & 0.487 & 0.396 & 0.148 \\
\hline SWilk W & 0.965 & 0.860 & 0.830 \\
\hline SWilk Probability & 0.860 & 0.190 & 0.107 \\
\hline
\end{tabular}

Table 10: Descriptive statistical analysis parameters of SS, BH and ET on RP. HPLC accuracy results.

1. Hockley B, Johnson NM (1983) Fenoterol versus salbutamol nebulization in asthma. Postgrad Med J 59: 504-505.

2. Flatt A, Crane J, Purdie G, Kwong T, Beasley R, et al. (1990) The cardiovascular effects of beta adrenergic agonist drugs administered by nebulisation. Postgrad Med J 66: 98-101.

3. Tantucci C, Duguet A, Similowski T, Zelter M, Derenne JP, et al. (1998) Effect of salbutamol on dynamic hyperinflation in chronic obstructive pulmonary disease patients. Eur Respir J 12: 799-804.

4. Mahler DA1 (2002) The effect of inhaled beta2-agonists on clinical outcomes in

chronic obstructive pulmonary disease. J Allergy Clin Immunol 110: S298-303.

5. Baldwin DR, Sivardeen Z, Pavord ID, Knox AJ (1994) Comparison of the effects of salbutamol and adrenaline on airway smooth muscle contractility in vitro and on bronchial reactivity in vivo. Thorax 49: 1103-1108.

6. Prakash YS, van der Heijden HF, Kannan MS, Sieck GC (1997) Effects of salbutamol on intracellular calcium oscillations in porcine airway smooth muscle. J Appl Physiol (1985) 82: 1836-1843.

7. Bai Y, Sanderson MJ (2006) Airway smooth muscle relaxation results from a reduction in the frequency of $\mathrm{Ca} 2+$ oscillations induced by a cAMP-mediated inhibition of the IP3 receptor. Respir Res 7: 34.

8. British Pharmacopoeia (2009) Her Majestys Stationary Office, London, UK.

9. Santoro M, Dos Santos M, Magalhaes J (1983) Spectrophotometric determination of bromhexine hydrochloride in pharmaceutical preparations Journal-Association of Official Analytical Chemists 67: 532-534.

10. Rao EV, Rao GR, Raghuveer S, Khadgapathi P (1987) Gas-liquid chromatographic and ion-pair high-performance liquid chromatographic determination of pseudoephedrine hydrochloride and bromhexine hydrochloride in pharmaceuticals. Analyst 112: 871-874.

11. Zarapkar SS, Rele RV, Doshi VJ (1988) Simple spectrophotometric methods for the estimation of bromhexine hydrochloride. Indian Drugs 26: 38-41.

12. Naidu N, Naidu D, Rajeswari C, Naidu P (1989) A simple spectrophotometric determination of salbutamol sulfate in pharmaceutical formulations. Acta chimica hungarica-models in chemistry 126: 821-824.

13. Talwar N, Singhai AK, Shakya AK, Saraf S, Jain NK (1991) Difference spectrophotometric determination of salbutamol sulphate in tablets. Indian Drugs 28: 244-245.

14. Gala B, Gomez-Hens A, PerezBendito D (1993) Direct kinetic determination of bromhexine hydrochloride in pharmaceutical formulations. Analytical letters 26: $2607-2617$

15. Lemus Gallego JM, Prez Arroyo J (2002) Spectrophotometric determination of hydrocortisone, nystatin and oxytetracycline in synthetic and pharmaceutical preparations based on various univariate and multivariate methods. Analytica Chimica Acta 460: 85-97.

16. Dave HN, Mashru RC, Thakkar AR (2007) Simultaneous determination of salbutamol sulphate, bromhexine hydrochloride and etofylline in pharmaceutical formulations with the use of four rapid derivative spectrophotometric methods. Anal Chim Acta 597: 113-120.

17. ICH (1996) International Conference on Harmonization, Q2B Validation of Analytical Procedures: Methodology, Consensus Guidelines, ICH Harmonized Tripartite Guidelines.

18. ICH (1994) International Conference on Harmonization, Q2A Validation of Analytical Procedures: Consensus Guidelines, $\mathrm{ICH}$ Harmonized Tripartite Guidelines. 